urethral diverticula. Urol Clin North Am. 2002;29:341-8.

5. Khan RA, Wahab S, Ullah E. Clinics in diagnostic imaging (130). Congenital megalourethra. Singapore Med J. 2010;
51:352-5.

6. Appel RA, Kaplan GW, Brock WA, Streit D. Megalourethra. J Urol. 1986;135:747-51.

\section{N-Acetyl Cysteine in Non- Acetaminophen Pediatric Acute Liver Failure: Recent evidence !}

We read with interest the current consensus statement on management of acute liver failure in infants and children [1]. Pediatric acute liver failure (ALF) is a devastating disease in which previously healthy children rapidly lose hepatic function due to a variety of causes and become critically ill within days. Management is largely supportive and only few conditions are amenable to directed therapy, such as acute acetaminophen toxicity. $\mathrm{N}$-acetyl cysteine (NAC) replenishes mitochondrial and cytosolic glutathione stores and is the treatment of choice for acute acetaminophen toxicity. Studies in the past have shown some role of NAC in non-acetaminophen ALF $[2,3]$.

The writing committee stated that there is increasing evidence for use of NAC infusion in non-acetaminophen causes of ALF [1]. They recommended routine use of NAC in the dose of $100 \mathrm{mg} / \mathrm{kg} /$ day in all cases of ALF irrespective of the etiology. This was based on a retrospective single site review involving 170 children done by Kortsalioudaki, et al. [2]. In this study NAC was associated with a shorter length of hospital stay, higher incidence of native liver recovery without transplantation, and better survival after transplantation.

However, a recent well designed placebo controlled trial conducted by the Pediatric Acute Liver Failure Study Group does not support the broad use of NAC in nonacetaminophen Pediatric ALF [4]. This multi-centre trial included 184 children under the age of 18 years. The study group found that NAC did not improve 1-year survival in children with non-acetaminophen ALF. Oneyear liver transplant free survival was significantly lower in the NAC-treated group, especially among children less than 2 years of age with HE grade $0-1$. This study emphasized the importance of conducting prospective pediatric drug trials.

With the availability of new evidence in recent literature, indiscriminate use of NAC in all cases of pediatric ALF is not justified.

MANISH SHARMA AND NiSHANT VERMA
Department of Pediatrics,
All India Institute of Medical Sciences,
New Delhi110 029, India.
drnishantaiims@gmail.com

\section{REFERENCES}

1. Bhatia V, Bavdekar A, Yachha SK for the Pediatric Gastroenterology Chapter of Indian Academy of Pediatrics. Management of Acute Liver Failure in Infants and Children: Consensus Statement of the Pediatric Gastroenterology Chapter, Indian Academy of Pediatrics. Indian Pediatr. 2013;50:477-82.

2. Kortsalioudaki C, Taylor RM, Cheeseman P, Bansal S, Mieli-Vergani G, Dhawan A. Safety and efficacy of Nacetylcysteine in children with non-acetaminopheninduced acute liver failure. Liver Transpl. 2008;14:25-30.

3. Lee WM, Hynan LS, Rossaro L, Fontana RJ, Stravitz RT, Larson AM, et al. Intravenous $\mathrm{N}$-acetylcysteine improves transplant-free survival in early stage non-acetaminophen acute liver failure. Gastroenterology. 2009;137:856-64.

4. Squires RH, Dhawan A, Alonso E, Narkewicz MR, Shneider BL, Rodriguez-Baez N, et al. Intravenous Nacetylcysteine in pediatric patients with nonacetaminophen acute liver failure: A placebo-controlled clinical trial. Hepatology. 2013;57:1542-9.

\section{Should N-acetylcysteine be used in Treatment of Non-acetaminophen Pediatric Acute Liver Failure?}

In a recently published consensus statement on management of acute liver failure, the authors have recommended the use of $\mathrm{N}$-acetylcysteine in the treatment of children with non-acetaminophen pediatric acute liver failure [1]. Intravenous $\mathrm{N}$-acetyleysteine (NAC) was incorporated into the general management of acute liver failure following a small uncontrolled study suggesting improved cardiovascular hemodynamics and oxygen transport in liver failure in adults [2]. In pediatric population, NAC became popular after a retrospective 